\section{LETTER TO THE EDITOR.}

The Editor does not hold himself responsible for opinions ex. pressed by his correspondents. Neither can he undertake to return, or to correspond with the writers of, rejected manuscripts intended for this or any other part of NATURE. No notice is taken of anonymous communications.]

\section{Selenium in Sulphuric Acid.}

With reference to the article in NATURE on the beer poisoning epidemic (pp. 54I-542) as to the possibility of the presence of selenium, either conjointly with or preferentially to some compound of arsenic producing the calamity, the following observations may be of interest.

Some few years ago, in the course of an investigation on the inertness of the alkaline earths towards hydrochloric acid gas (Ber. Deutsch. Chem. Ges. xxix. 577-58c), I had occasion to use sulphuric acid (labelled puriss) as a dehydrating agent for the gas, but after passage of the gas for some time a red deposit of selenium was invariably observed at the bottom of the Drechsel wash-bottle containing the acid.

It would, of course, be impossible now to trace the past history of such samples of acid, which might have come from several manufacturers, but these observations may show that selenium is a far more common impurity even in the best samples of acid than hitherto supposed.

Though some of the ill-informed writers and politicians of today might be invited, as a form of hard labour, to obtain sulphuric or any other acid in a state of purity (credite experto), yet it is not apparent that this acid need be used for the preparation of invert sugar to be subsequently applied to the manufacture of beer.

V. H. VELEY.

Oxford, April 6.

\section{THE BOARD OF TRADE AND ELECTRIC LIGHTING.}

THE Board of Trade has been busily engaged during the past few weeks with two inquiries of great importance to the electric lighting industry. The decision arrived at in the one of these which dealt with the maximum price to be charged for electric energy has already been referred to in our issue of March 14 (p. 474). The other inquiry, which was opened on March I under the presidency of Sir Courtenay Boyle, occupied the attention of the Board of Trade for six days, and has raised some points of considerable technical and scientific interest. The Board has not, as yet, given its decision, but the hearing of evidence and the pleadings have been completed, and we propose briefly to review the expert evidence in the following article.

The object of the inquiry was to consider an application to the Board of Trade, made by various electric lighting companies and local authorities, notably by the Westminster Electric Supply Corporation, for an alteration in one of the Board of Trade regulations. The regulation in question provided that "no change should be made in the pressure of the supply to any premises ... except with the consent of the consumer." This regulation, it will be seen, gives to the consumer the absolute power to veto any change in the standard pressure of the supply to his premises, a change, for example, from 100 volts to 200 volts, which the supply company may desire to make. It was this power of veto that the companies wished to remove, and accordingly they made application for an alteration of the regulation by which for the words "with the consent of the consumer" should be substituted the words "on such terms and conditions as may be agreed upon between the undertakers and consumer, or, failing agreement, as may be settled by an arbitrator appointed by the Board of Trade," or words to that effect.

The difficulties which have led to this inquiry have all arisen out of the change from a I0o-volt to a 200-volt supply which is being made by the Westminster and other electric light supply companies. The change was started in the case of the Westminster Corporation, which we may take as a typical instance, in 1896 , and their reasons for making it were as follows. The system, as originally laid down, was a three wire system with IOO volts between each outer conductor and the middle; by 1895 the demand for electric light had increased so much that the street mains were beginning to get overloaded, that is to say, the current which they were obliged to carry was more than was economically good. The evil of this overloading was shown in two ways: on account of the heavy current which the mains were carrying the loss of energy in them, which is proportional to the square of the current, was very great, amounting, in fact, to about $12 \frac{1}{2}$ per cent. of the total output; also the drop of voltage in the mains was considerable and made it increasingly difficult to maintain the voltage at the consumer's terminals within the limits of variation allowed by the Board of Trade. In these circumstances, the supply company was faced with a difficulty which could be overcome only in two ways. Either they could put down fresh mains year by year to meet the increasing demand, a proceeding which would involve an expenditure of something like $7500 l$. a year, or they could supply the same amount of energy, using a smaller current and a higher voltage. If the voltage were doubled the same amount of energy would be supplied by only half the current, and the energy loss in the mains would be only one-quarter of its former amount; the drop of voltage would at the same time be halved (the percentage drop being therefore only one-quarter of its former value), and thus the second difficulty referred to above would be avoided. It is perfectly evident, therefore, that from the supply company's point of view the best course to adopt was to increase the standard voltage of the supply. And indirectly, also, this course must be beneficial to the consumers, and prospective consumers, for anything that tends to cheapen the cost of supply to the company tends also to lower the price the consumer has to pay for the energy he uses.

The consumer has, however, another way in which he can look at the question. It is not simply energy that he wishes to buy, but energy that can be economically converted into light ; in fact, he really wants simply to purchase light. If, therefore, the 200-volt lamp is less efficient than the roo-volt lamp, it may be to his disadvantage to have to use energy at 200 volts, even though the cost of such energy may be less. For example, if we may state a similar case, it is not an advantage to a consumer to be obliged to drink arsenical beer, although the cost may be less than that of pure beer. In addition, the change necessitates, in most cases, refitting and rewiring of the premises, since the fittings that are suitable for Ioo volts, especially if they are of old patterns, are not good enough for 200 volts, and also the wiring is often not good enough for the higher pressure. The question of the liability of the supply company for the costs of these alterations and for the inconvenience caused by the necessity of making them is, however, one which can reasonably be settled by arbitration. The matter of prime importance to the consumer is, we consider, the question of the inferiority -real or alleged-of the light obtained with 200-volt lamps.

Before the Westminster Corporation decided to make the change, they ascertained to their own satisfaction that the 200-volt lamps were as good as the Ioo-volt, or, if not as good, so little inferior that the disadvantage was more than counterbalanced by the lowering of the price charged to the consumer. This is a point, however, on which doctors disagree, as was shown by the expert

No. I 642 , VOL. 63$]$ 
evidence at the inquiry, and it is interesting to note the grounds given for the various opinions held.

Prof. Kennedy, who is adviser to the Westminster Corporation, advanced the argument that if the 200-volt lamp were really less efficient than the roo-volt, then the consumption of energy per lamp connected to the mains should have steadily increased since 1897 , as more and more consumers were changed over to the higher pressure. But this argument is, as Prof. Ayrton pointed out, quite fallacious ; if the consumer is supplied with a 200 -volt so-called 8 c.p. lamp, which is, in reality (as in an actual case quoted by Prof. Ayrton), only giving a candle-power of 1.8 and is consuming 15.3 watts per candle, it will only consume 28 watts ; the consumption of energy is therefore rather less than with a Ioo-volt 8 c.p. lamp giving its correct candle-power and consuming 4 watts per candle. The consumption of energy per lamp in cases like this goes down, from which Prof. Kennedy would argue that the efficiency has gone up; whereas, as a matter of fact, it has diminished enormously, the effect appearing, not in an increased bill, but in a decrease of light. As a matter of fact, this is the way in which the inefficient lamps show their badness ; they do not maintain their correct candle-power and take more watts, but they fall off in candle-power for the same consumption of energy. This was exemplified in the evidence given by Mr. B. M. Drake. Most engineers and lamp-makers call the watts consumed per candle by the lamp its efficiency, though, as a matter of fact, this quantity is a measure of the inefficiency. $\mathrm{Mr}$. Drake prefers to measure the inefficiency by the complaints received per customer, and there can be no doubt that, though unscientific, this is a very good way of getting at an average value. According to this standard, $\mathrm{Mr}$. Drake finds that the 200-volt lamp is much inferior to the roo-volt.

There was not wanting evidence in favour of the 200volt lamp, but the majority of the experts, certainly in the cases in which the results of actual tests were given, were against it. To take one other instance, Mr. Gunyon, on behalf of the London County Council, gave evidence to the effect that the 200-volt lamp cost more, lasted for fewer hours, and was less efficient than the roo-volt; he gave the results of tests on four different makes of 200-volt lamps, the average consumption of energy in the new lamps coming out at $5^{\circ} 4,4^{\circ} \mathrm{I}, 5^{\circ} 8$ and $5^{\circ} 6$ watts per candle respectively, the good value $\left(4^{*} \mathrm{I}\right)$ being for a foreign make of lamps. These figures show that lamp-makers have by no means yet got over the difficulties of the manufacture of the 200-volt lamp which were pointed out by Mr. Byng in a paper read before the Institution of Electrical Engineers three years ago (Journal of the Institution of Electrical Engineers, I898, vol. xxvii. p. I I8). That they will ultimately triumph over the difficulties all must hope ; that they have satisfactorily done so now cannot, we think, be maintained.

The inferiority of the high-voltage lamp is, however, as we have pointed out, not the only consideration; the change is, without doubt, beneficial to the supply company, and it must, moreover, be remembered that in many cases the change has been all but completely carried out. The Westminster Corporation have only some half a dozen consumers who are still being supplied at the low pressure ; the remainder, either through choice, through indifference, or through ignorance of their power to refuse, have submitted to the change. No doubt these few outstanding consumers are an annoyance to the company and a source, possibly, of loss, although the company have raised the price they are charging them to the maximum allowable; yet we cannot help sympathising with the consumer who objects to being compelled to use what he honestly, and with justice, believes to be a worse article.

No. I 642, VOL. 63$]$
SEISMOLOGY IN JAPAN.

THE chief interest attached to the publications mentioned below ${ }^{1}$ is the fact that while giving us an insight into the attitude taken by the Government of Japan in regard to seismology, they form an important link in the history of the modern development of that subject.

On February 22, I880, a rather severe earthquake so far excited the curiosity of the inhabitants of Tokyo and Yokohama that, with the object of studying such tremblings, a Seismological Society was founded. This society existed for twelve years and published twenty volumes. The usefulness of its work, attracting the attention of the Japanese Government, led to the establishment of a chair of seismology at the Imperial University, and the organising of a bureau which now controls nearly Iooo observing stations. The next great stimulus that seismology received came from the terrible disaster of October 28, 1891. Ten thousand persons were killed, more than fifteen thousand were wounded, and thirty million dollars' worth of property were destroyed. A comparison of the buildings which remained standing with those which were shattered and those which were utterly ruined indicated that something might be done to minimise such disasters, and to accomplish this, by virtue of an Imperial Ordinance, on June 25, 1892, an Earthquake Investigation Committee was established. This body consists of some twenty-eight members selected from amongst the best-known engineers, architects and men of science in Japan. Two well-known names-Prof. D. Kikuchi and Dr. F. Ōmori-appear as president and secretary. The modus vivendi, which can be seen in the Parliamentary Budget, seems to have an annual variation of from $1000 l$. to $5000 /$. Amongst the various investigations which this committee proposed to undertake we find the following:-

To collect documents relating to seismology and volcanology; to draw up a statistical account of seismic phenomena in Japan, such, for example, as might be required by insurance companies whose risks extend to disasters caused by earthquakes ; to conduct geological researches bearing upon seismology; to extend our knowledge respecting the nature of earthquake motion; to determine the velocities with which earthquakes are propagated from point to point; to make observations on changes in the vertical and earth "pulsations"; to compare the movements resulting from given earthquakes as recorded on the surface of the earth and at depths which are comparable with the depths to which foundations of buildings may be carried ; to extend observations on the variability of magnetic elements, there being reasons to believe that these may hold a certain relationship to seismic activities; to observe changes in temperature at great depths; to determine strength constants for building materials produced in Japan; to measure accelerations and maximum velocities necessary for the shattering, overturning or projection of various bodies, amongst which no less than sixteen types of model houses are specified; to erect buildings specially designed to resist earthquakes; to study the effects of earthquakes on modern construction and generally the committee undertook to make any investigation which may ultimately result in reducing the loss of life and property which so frequently accompanies violent earthquakes.

Although only nine years have elapsed since this elaborate programme was formulated, every item in it has received serious attention.

From volumes iii. and iv. we see that Profs. Tanabe and Mano have worked at the strength constants of

1 Publications of the Earthquake Investigation Committee in Foreign Languages. No. 3 , pp. I03; No. 4, pp. 14 I ; No. 5 , pp. 82 ; and No. 6 , pp. 18r. (Tokyo, rgoo-rgor.) 